\title{
The Construction of Online Education and the Balanced Development of Compulsory Education in the Post- Epidemic Era: A Case Study in China
}

\author{
Huaqin $\mathrm{Zhu}^{1}$ Huajun $\mathrm{Li}^{2, *}$ \\ ${ }^{1}$ Collge of Teacher Education, Zhaoqing University, ZhaoQing Guangdong 526061, China \\ ${ }^{2}$ Collge of Economics \& Management, Zhaoqing University, ZhaoQing Guangdong 526061, China \\ *Corresponding author. Email: lhj33118@163.com
}

\begin{abstract}
In recent years, China has made important achievements in the balanced development of urban and rural compulsory education and the construction of education information. Under the COVID-19 epidemic, the social experiment of nationwide information-based teaching and the movement of educational resources opening have also exposed some problems in the above two fields. Based on the review of the current situation of the balanced development of compulsory education, this paper further analyzes the new challenges faced by the online education construction in promoting the balanced development of compulsory education in urban and rural areas under the epidemic background, and puts forward relevant measures to deal with the challenges.
\end{abstract}

Keywords: Post-epidemic era; Online education; Compulsory education in urban and rural areas; Balanced development

\section{INTRODUCTION}

Education informatization can improve education equity and promote education balanced development to a certain extent, which has become the consensus of the education and academic field ${ }^{[1-3]}$. At the same time, some scholars point out that the development of information technology will bring about a new digital divide and may lead to new educational inequity ${ }^{[4-6]}$. With the outbreak of COVID-19 epidemic in China, the policy requirement of "postponement of school without suspension of learning" has made online education a rigid demand and promoted a nationwide information-based teaching social experiment and open educational resources movement. These experiment and movement review the education informatization reform and teachers' ability of information technology, and prompted a great discussion on how to deepen the development of online education reform in the post-epidemic era. Online education during the antiepidemic period has achieved important results in ensuring the orderly development of education and teaching at all levels and in all kinds, and in promoting the deepening reform of teaching models, but it also exposes the new problems and challenges that the educational informatization construction and online teaching have brought to the balanced development of compulsory education, as well as provides an opportunity and inspiration for how to construct online education in the post epidemic era ${ }^{[7-9]}$.

\section{BALANCED DEVELOPMENT OF COMPULSORY EDUCATION IN CHINA}

As seen in Table 1, 95.32\% of the counties in China were up to the national standard of basic balanced development, according to the 2019 National Compulsory Education Balanced Development Supervision and Evaluation Report. There are still 136 counties in 9 provinces that have not been approved, which are mainly distributed in poor areas, ethnic minority areas and remote areas ${ }^{[7]}$.

Table 1 Counties' compulsory education balanced development conditions in China (2019)

\begin{tabular}{lcc}
\hline Types & $\begin{array}{l}\text { County } \\
\text { numbers }\end{array}$ & Percentages \\
\hline $\begin{array}{l}\text { Up to the } \\
\text { standard* }\end{array}$ & 2767 & 95.32 \\
\hline $\begin{array}{l}\text { Not up to the } \\
\text { standard* }\end{array}$ & 136 & 4.68 \\
\hline Total & 2903 & 100 \\
\hline
\end{tabular}

*national standard of basic balanced development

The data mentioned above shows important achievements been made in the development goal of basic equilibrium in compulsory education, as well as reflects that the main problem that the basic balance in compulsory education has not been fully realized lies in regions and mountainous areas with underdeveloped economy and backward transportation facilities. So, the poor foundation and weak 
security in these regions have become the development bottleneck.

The development task of compulsory education is still arduous from the perspective of compulsory education's quality and balanced development. Compared with the basic balance, the connotation of high-quality balance will be embodied as follows: a clearer concept of all-round development, a higher degree of standardization, a stronger contingent of teachers, and greater satisfaction of the people. In order to ensure the implementation of the above standards, the office of the State Council's Education Steering Committee has formulated measures for the supervision and assessment of the balanced development of high-quality county-level compulsory education, such as the basic principles of "Focusing on hardware but more on software, focusing on indicator qualification but more on mass satisfaction, and focusing on quantity but more on quality"[10].

From the above principles, they indirectly reflect that several important problems in the development process of compulsory education still need to be solved or further deepened, such as education information construction, teaching staff construction, teaching quality construction, curriculum resources construction. These problems have also been fully exposed in the course of the online education throughout the country during the epidemic.

\section{CHALLENGES TO BALANCED DEVELOPMENT OF COMPULSORY EDUCATION UNDER EPIDEMIC}

\subsection{Challenges brought by differences in the educational informatization}

According to the 2015 OECD online learning report, with the rapid development of global informatization, children from low-income families in most countries had more access to the Internet, but the educational gap among students has not narrowed, the "new digital divide" was gradually widening ${ }^{[4,9,11]}$.

From the perspective of education starting point fairness, the difference of educational information-based equipment level and infrastructure construction is the "first digital divide"[12]. For rural areas, due to the economic conditions of their families and the local network infrastructure, some students in these areas could not guarantee the "suspension of classes" during the epidemic. Some even had to climb to the roof or the top of the mountain to have classes and sit in the field to look for signals. In terms of the fairness of education process, the difference brought about by the use of educational information technology is the "second digital divide". During the epidemic, schools with poor infrastructure and poor security in rural and poor areas remained in the stage of unified viewing of "classroom in the sky". Besides these schools, there were also great differences in the application of educational information technology tools and platforms between undeveloped regions and developed regions as well as within regions. In the context of urban-rural dual economy and society, and in the development stage of education informatization 2.0, the above two digital gaps still exist, which will become an important challenge to realize the basic balanced development of urban and rural compulsory education and further strengthen the balanced development of quality. From the perspective of educational outcome fairness, there are also differences in the degree of benefit from online education among different social strata. An analysis of the results of a MOOC study found that children from disadvantaged families had significantly lower participation and completion rates.

\subsection{Challenges brought by differences in the teaching staff structure}

Online education requires high comprehensive quality of teachers, including high information literacy, strong integration ability and highly reflective practical ability, in addition to the mastery and application of basic educational information technology and tools. However, at present, there are some problems in the structure of rural teachers, such as the lack of teachers, the structure of teachers' academic qualifications and the structure of knowledge system, which have been important factors leading to the inequity of urban and rural education quality for a long time. At the same time, traditional teacher information technology training pays too much attention to how to promote the integration of information technology and teaching, and not enough attention to how to improve the ability to process educational information resources. In addition, from the perspective of online education during the epidemic period, schools and teachers in these regions could not solve the emergent problems such as technical failures of online teaching in a timely manner, which affected the normal development of online teaching. In recent years, the comprehensive reform in education and the development of rural teacher education have made some achievements in alleviating the shortage of teachers in rural areas. However, the online education during the epidemic exposes new problems, that is, the size of the rural teachers and the structure of their education and knowledge system.

\subsection{Challenges brought by differences in the teaching quality}

Although the current level of educational technology and educational informatization are constantly maturing, but many forms of internet-based instruction, such as rollover classroom and MOOC, can only be carried out in developed regions and high-quality schools. The outbreak of the epidemic forced the full outbreak of the information education revolution, which also conducted an in-depth test of the education information construction in advance. During the epidemic period, a variety of unexpected 
problems in the online teaching process, as well as the plight of rural teachers in backward areas and other issues, reveal the challenge of balanced development of urban and rural education brought by the difference of economic development level and teaching quality level.

Although the network has been basically popularized in China, high quality teachers and advanced network equipment are the prerequisite for online education. For the schools in rural and mountainous areas with low levels of economic development, except for the backward educational infrastructure and the lagging information literacy and ideas, the application of educational technology has not been incorporated into daily teaching; this has led to differences in the teaching quality and will further hamper the balanced development of the compulsory education.

\subsection{Challenges brought by differences in the resource construction and sharing}

The online education under the epidemic and the policy of "postponement of school without suspension of learning" have promoted the construction and sharing of curriculum resources nationwide in China. The Ministry of Education has integrated the national and some provincial and municipal online learning platforms to ensure that teachers and students can make use of various terminals to receive resources such as televisions, computers, mobile phones and tablets; it takes into account the needs of all provinces, cities and regions, especially rural and remote poor areas. How to make overall planning and implementation guidelines at the national, provincial and municipal levels to promote the construction and sharing of curriculum resources has become another major challenge in the postepidemic era to promote the balanced development of the compulsory education. For the areas where the current level of curriculum resources construction and the level of education quality are not high, the policies and guidelines related to online education during the epidemic period have not been synchronized or coordinated effectively; as a result, there are differences in the organization, selection and promotion of the construction of high-quality curriculum resources. These differences, together with the above-mentioned factors affecting the level of public infrastructure for education and information technology, as well as the problems of the online education industry and application platforms under the epidemic, they may lead to new problems in the balanced development of urban and rural compulsory education in the post epidemic era.

\section{Countermeasures for Balanced Development of Compulsory Education in the Post-Epidemic Era}

\subsection{Accelerate the new infrastructure to ensure the educational equity and quality}

The "new infrastructure", represented by $5 \mathrm{G}$, artificial intelligence, industrial internet and Internet of things, has entered the fast lane, which provides an opportunity for the development of networking, digitalization and intelligentization in education. Therefore, in the postepidemic era, the government should strengthen the construction of education information infrastructure, enhance the large-scale supply capacity of education information, eliminate poverty and the "last mile" bottleneck of information in remote areas, and let the "new infrastructure" of education become the key to fill up the shortage of infrastructure, information resources and the application of technology. Furthermore, the government should support the construction of $5 \mathrm{G}$ facilities in rural or remote areas by preferential policies and cost subsidies.

\subsection{Strengthen the systematic and coordinated construction of quality curriculum resources}

The government should fund the construction of a highquality free platform of national online education resources and improve the systematization level of curriculum resources to correct the fragmentation in the process of construction. More social forces should be encouraged to supply the top-quality online education courses through preferential policies and financial subsidies, and a reasonable evaluation and selection mechanism should be established. In the process of accelerating the "new infrastructure" of education, an experimental area for the balanced development of compulsory education should be explored and set up, in which live teaching platform design and curriculum system sharing activities should be carried out, as well as the establishment of "school-school" pairs to help improve the educational informatization in rural areas.

\subsection{Optimize the pre-employment education and post-employment training of rural teachers}

First of all, the government should enlarge the enrolment scale of majors related to educational technology and educational information in normal colleges and universities, and coordinate with rural teacher training programs. Secondly, colleges and universities should combine the Internet, big data and other models to improve the existing training programs and curriculum system, optimize the integration development path of online education and education information. Finally, the 
government, universities and primary and secondary schools jointly set up an education technology application ability training system which integrates pre-service education and post-service training.

\subsection{Strengthen the co-construction and collaborative governance of platform and system}

Due to the strong externality of online educational resource, the mechanisms of classified development, coconstruction and co-governance should be effectively established among resource builders, resource users and fund providers thus urge the stakeholders in the mutual coordination to do their best. The national free public platform should be built by the government, entrusted with the third party operation, supported by the corresponding curriculum resources access mechanism and dynamic evaluation mechanism. Correspondingly, the social profitable platform should be built according to the following principles or mechanisms: access after government evaluation, supply after enterprise competition, and independent choice of schools.

\section{CONCLUSION}

The outbreak of COVID-19 epidemic and related policy of "postponement of school without suspension of learning" tested the effectiveness of China's online education and education informatization efforts, and exposed the challenges to the balanced development of urban and rural areas. In the post-epidemic era, it is necessary to carry out systematic construction and collaborative governance in the areas of new infrastructure, resource platform, curriculum system, teaching staff and application model, so as to promote the development of online education and education informatization and enhance the compulsory education quality and balanced development.

\section{ACKNOWLEDGMENT}

This research was financially supported by the Philosophy and Social Science Project of Zhaoqing (20ZD-03).

\section{REFERENCES}

[1] He Kekang.Educational informationisation:The only way to the high quality and balanced development of compulsory education[J].Modern Distance Education Research,2011(04):16-21.

[2] Brown M G, Wohn D Y, Ellison N. Without a map: College access and the online practices of youth from low- income communities[J]. Computers \& Education,2016,9293:104-116.

[3] Zhang Weiping,WANG Jixin.Problems, models, and suggestions for promoting a balanced development of compulsory education in rural areas through educational informatization:Based on the survey of 20 unties (districts) in 8 Chinese provinces[J].Open Education Research,2018,24(01):103-111.

[4] Li Y, Ranieri M.Educational and social correlates of the digital divide for rural and urban children:A study on primary school students in a provincial city of China[J].Computers\&Education, 2013, 60 (1) :197-209.

[5] Vekiri I.Socioeconomic differences in elementary students' ICT beliefs and out-of-school experiences[J].Computers\&Education, 2010, 54 (4) :941950.

[6] Brandtzg P B, Heim J, Karahasanovic A.Understanding the new digital divide:A typology of Internet users in Europe[J].Internationa Journal of Humancomputer Studies, 2011, 69 (3) :123-138.

[7] Tian Jun,Chen Lanzhi.Characteristics,problems of "postponement of school without suspension of learning" during the anti-epidemic period and development trend of online education in the post-epidemic era[J]. Teacher Education Forum,2020,33(04): 4-8.

[8] Tao Mengyun.Analysis of problems in online education of primary and secondary schools under the COVID-19 epidemic[J]. Education Science Forum,2020(14): 39-41.

[9] Lei Wanpeng,Huang Xuzhong.Problems in the development of online education under the COVID-19 epidemic[J]. Education Research and Experiment,2020(02): 13-16+22.

[10] Fu Weidong,Zhou Hongyu.Challenges brought by the COVID-19 epidemic to online education in China and coping strategies[J].Journal of Hebei Normal University(Educational Science),2020,22(02):14-18.

[11] OECD. Student, computers and learning:making the connection[M].Paris:OECD Publishing,2015.

[12] Attewell P. The first and second digital divides[J]. Sociology of Education,2001,74(3). 